\title{
Cascade Optimization using Controlled Random Search Algorithm and CFD Techniques for ORC Application
}

\author{
Ramiro G. Ramirez Camacho ${ }^{1} \quad$ Edna R. da Silva ${ }^{2} \quad$ Konstantinos G. Kyprianidis $^{3} \quad$ Oliver Visconti $^{4}$ \\ ${ }^{1}$ Mechanical Engineering Institute, UNIFEI - Federal University of Itajubá,Itajubá, Brazil, ramirez@unifei.edu .br \\ ${ }^{2,}$ Future Energy Center, MDH Mälardalen University, Västerås, Sweden, ednauni fei@yahoo.com.br \\ ${ }^{3}$ Future Energy Center, MDH Mälardalen University, Västerås, Sweden, konstantinos.kyprianidis@mdh.se \\ ${ }^{4}$ Mechanical Engineering Institute,UNIFEI - Federal University of Itajubá, Itajubá, Brazil, oliver@unfei .edu.br
}

\begin{abstract}
This paper presents the methodology for performance optimization of a steam turbine cascade using CFD techniques for ORC (Organic Rankine Cycle) application. The steam turbine cascade is parameterized to achieve the maximum efficiency while using different organic fluids. The main objective of this work is to attain the maximization $C_{l} / C_{d}$ ratio from a preliminary design. The approach to finding the maximum $C_{l} / C_{d}$ ratio is based in optimization algorithms. The CRSA (Controlled Random Search Algorithm) was chosen for the optimization process. The optimization algorithm (CRSA) is integrated with CFD techniques, using automatic building schemes of parameterized geometries and meshes via "script files" with editing commands written in Tlc/Tk language, which will be interpreted by the commercial software ICEM$\mathrm{CFD} \AA$, in batch mode. Finally, for the numerical calculation, the commercial software FLUENT ${ }^{\circledR}$ is used with fluid properties, real gas model, turbulence model and boundary conditions set through "journal files". In this paper, R245fa and Toluene are used as working fluids. Results of drag, lift and pressure distribution are reported. This methodology allows making corrections in the initial project of the cascade shape.
\end{abstract}

Keywords: ORC, optimization, CFD, CRSA, turbomachinery, real gas, equations of state

\section{Introduction}

The accelerated consumption of fossil fuels has caused many serious environmental problems such as the destruction of the ozone layer, global warming and air pollution. Emissions of carbon dioxide related to energy consumption have increased worldwide from 30.2 billion metric tons to 35.2 billion metric tons in recent years and will be around 43.2 billion metric tons in 2035 .

Given that energy resources are becoming more valuable due to the supply and demand relationship and that environmental legislation is becoming stricter, unconventional technologies for energy conversion are necessary to ensure the future supply of electricity. Low- grade heat sources are considered as candidates for new sources of energy.

The technologies for generating electrical power by recovering waste heat sources can be considered a wellestablished and mature way of energy production; taking into account that the thermodynamic cycles being more exploited are those using steam turbines, with the conventional Rankine Cycle as the most used due to its advantages, such as price, availability and non-toxicity of the working fluid. However, for heat sources with temperatures below $4000 \mathrm{C}$, it is quite difficult to use water as the working fluid because of the need to apply vacuum in a large part of the plant, making it less efficient and increasing generation costs considerably.

Accordingly, the Organic Rankine Cycle (ORC) is commonly used to generate energy from sources of low and medium temperature (geothermal, waste heat from processes, solar energy, etc.) and in recent decades has extended its use to sources of heat at high temperatures (biomass burning and exhaust gases from primary triggers).

The majority of the researches conducted in this field is focused on extensive analysis of different thermodynamic cycles and working fluids, seeking to develop energy systems more efficient by selecting the most appropriate organic working fluid and an optimal set of operating parameters.

However, the majority of these studies have different insights when defining the optimal set of criteria leading to an optimal configuration of the cycle according to the characteristics of the source of heat available. Furthermore, most of which rule out the possibility of analyzing the effects of the variation of various operating parameters of the cycle have on other indicators of interest, as the size and efficiency of the turbine, for example.

In this sense, researchers have committed a lot of efforts to develop methods for optimal design based on genetic algorithms to find the best design point. Recently, (Lemort et al., 2009) dealt with a method of maximizing the efficiency of the steam turbine based on genetic algorithms (Qin et al., 2003). This method has a number of functions that are taken as constraints. Thus the optimal geometry 
and aerodynamic parameters are solved using the genetic algorithm.

Researchers are more and more using CFD techniques because through certain defined geometry and with the use of correct boundary conditions, it is possible to calculate the local and global variables of the flow field.

The fundamental basis of almost every CFD problem is the Navier-Stokes equations, which define any singlephase fluid flow. However, it is not possible to only use CFD techniques when dealing with a great number of geometric and flow parameters. Then, in order to attain the correct solution, it is best to use an optimization algorithm (OA).

\section{Organic Rankine Cycle (ORC)}

The organic Rankine cycle (ORC) is similar to the conventional Rankine cycle power conversion. However, this system uses a high-density organic compound as the working fluid instead of water.

Saturation curves for water and an organic fluid are presented in Figure 1. The advantages provided by water and the organic fluids in each application are directly related to the observed differences in their saturation curves. More specifically, the large difference between both types of fluid is in the slope of the saturation vapor curves, which directly influences the behavior of the fluid during its expansion through the turbine. In the case of water, the vapor curve displays a negative slope (Figure 1a). However, the vapor curve of many organic fluids, exhibits a positive slope (Figure 1b). The expansion in the turbine takes place for the three types of fluid differently. In the case of water, the saturated vapor enters the turbine and undergoes an isentropic expansion to the condensing pressure of the cycle, the fluid output exhibits a high fraction of liquid (from the point of view of conservation of the internal structure of the turbine). Thus, the employment of overheating and reheat in the cycle becomes indispensable, in order to avoid the deterioration of the equipment, introducing complications to the system design. In the case of an organic fluid, superheated steam is obtained after expansion in the turbine, rather than a liquidvapor mixture. The absence of liquid along the turbine translates into a simpler system design, since there is no need for superheat and reheats in the cycle. Furthermore, because the fluid exiting the turbine is superheated, its temperature is higher than the condensing temperature, even though its pressure is identical to the condensing pressure. The appearance of the higher temperature, creates a potential heat transfer; enabling the use of part of the existing energy for preheating the fluid in the inlet of the steam generator. By harnessing the energy output of the turbine, it is possible to increase the cycle efficiency.

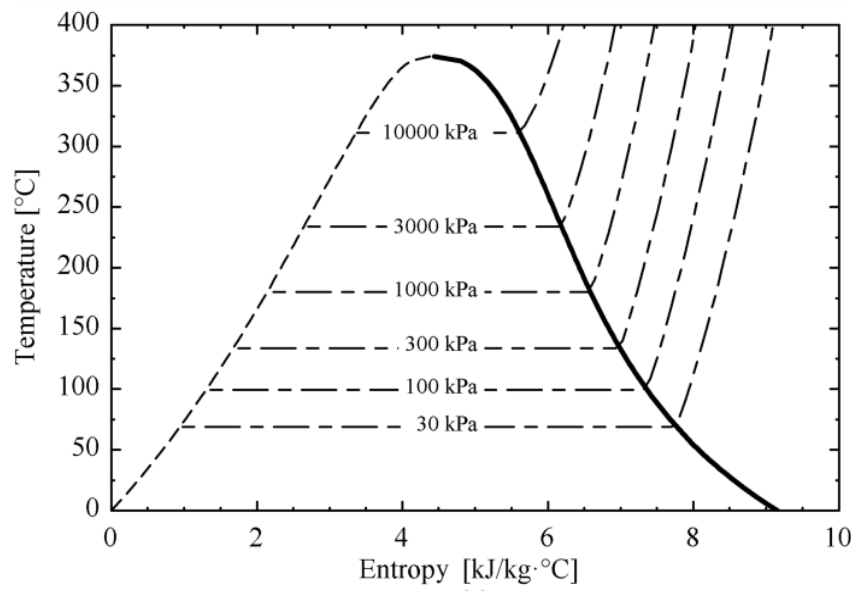

(a)

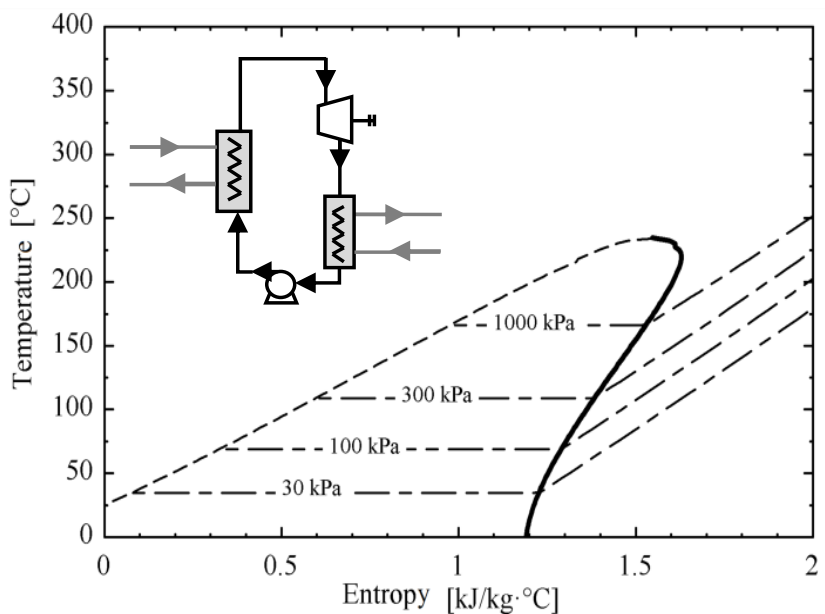

(b)

Figure 1. T-s diagrams for water (a) and an organic fluid (b), showing the different inclinations of the saturation vapor curve (continuous line).

In the last two decades, the use and research on this technology have grown rapidly as an option for recovering heat from sources of low temperature and medium temperature, such as solar energy, geothermal energy and waste heat from industrial processes. Today has extended its use for small cogeneration plants using biomass as fuel. Currently, it is expected that applications in industrial processes and modular applications using solar energy will have a rapid development in the coming years. Figure 2 shows one configuration of an ORC cycle, and the processes represented in a T-s diagram for two different flow as R245fa and Toluene.

The market facilities ORC is growing apace. Since the installation of the first plants of ORC in the 80s, has been registered an exponential growth in the use of this technology and in Europe currently, there are between 120 and 150 ORC plants (Crowe, 2011). According (Quoilin and Lemort, 2014), the growth in the number of projects and installed power of ORC in the last 20 years had an exponential character of which $48 \%$ corresponded to 
biomass applications, $31 \%$ geothermal, $20 \%$ heat sources residual and $1 \%$ with solar energy installations.

The ORC system performance is strongly connected to the prime mover, which are classified into two types: positive displacement expanders and turbo machinery. They can be used both axial and radial turbines, being the radial the one that ensure greater isentropic efficiencies in small capacities. The choice of prime mover should be made according to the size of the system. For small applications are used screws and scroll expanders which are in a stage of research and development as seen in the work of (Quoilin et al., 2010; Lemort et al., 2009) and others. While in applications above $200 \mathrm{~kW}$ are used axial turbines, with a high degree of technology maturity, which can reach isentropic efficiencies of up to $85 \%$.

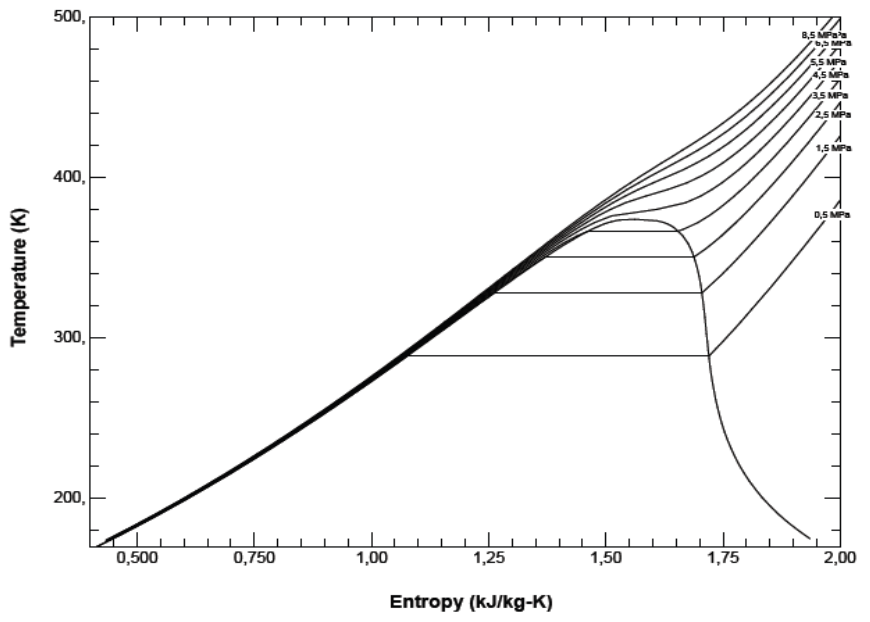

(a)

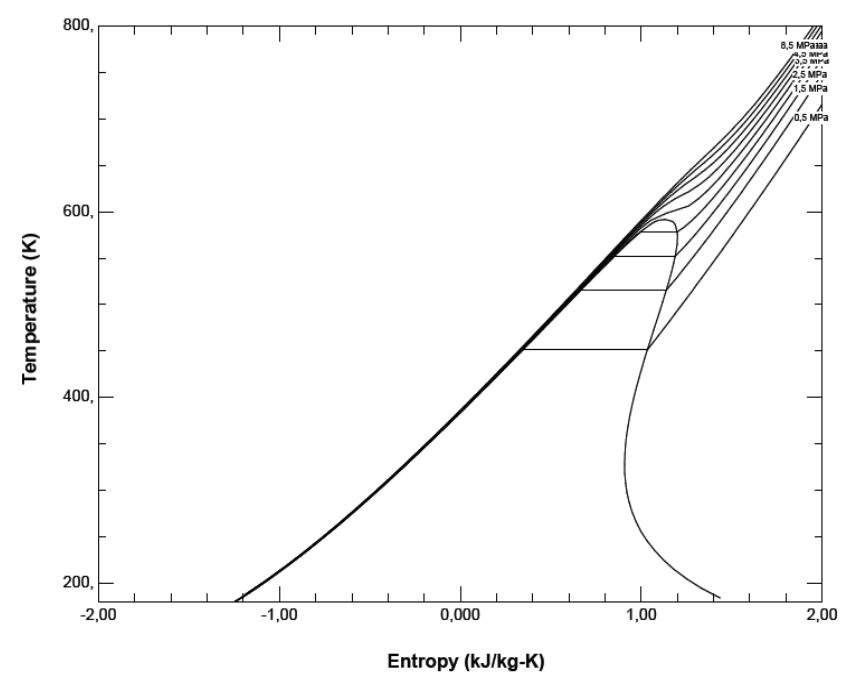

(b)

Figure 2. T-s diagrams showing the different inclinations of the saturation vapor curve to organic fluids, R245fa (a); and to organic fluids, toluene (b).

\section{Steam Turbine Design}

\subsection{Preliminary Turbine Design}

The preliminary design of a turbine begins using onedimensional modeling techniques. The thermoaerodynamic design of a turbine involves handling a large amount of parameters associated with mechanical calculations to obtain the final geometry for the context in which the turbine is intended. In general, the design consists in the search of some basic geometrical parameters for the rotor blades - the design variables - in order to maximize the turbine efficiency.

In this study, the preliminary design of the turbines was performed using an in-house code and following the design procedure established by (Saravanamutto et al., 2001). The general procedure implemented was to determine the overall dimensions of the machine along with blade and flow angles and isentropic efficiency by fixing the mass flow rate, inlet and outlet pressures as calculated by the cycle analysis and by assuming flow and loading coefficients (Table 1).

Table 1. Turbine Initial Design Operating Conditions.

\begin{tabular}{|l|l|}
\hline \multicolumn{2}{|c|}{ Operating Conditions } \\
\hline Mass flow & $\mathrm{m}=20 \mathrm{~kg} / \mathrm{s}$ \\
\hline Isentropic efficiency & $\eta \mathrm{t}=0.9$ \\
\hline Inlet temperature & $\mathrm{T}_{01}=1100 \mathrm{~K}$ \\
\hline Variation of temperature & $\Delta \mathrm{T}_{0}=145=\mathrm{T}_{01}-\mathrm{T}_{03} \mathrm{~K}$ \\
\hline Variation of Pressure & $\Delta \mathrm{P}=1.873=\mathrm{P}_{01} / \mathrm{P}_{03}$ \\
\hline Pressure inlet & $\mathrm{P}_{01}=4 \mathrm{bar}$ \\
\hline Rotation & $\mathrm{n}=250 \mathrm{rps}$ \\
\hline Peripheral velocity & $\mathrm{U}=340 \mathrm{~m} / \mathrm{s}$ \\
\hline Loss coefficient in the stator & $\lambda_{\mathrm{N}}=0.05$ \\
\hline Load Coefficient & $\phi=0.8$ \\
\hline
\end{tabular}

From the basic design specifications and the performance analysis, a refinement of the results was performed in order to optimize the geometry (Table 2).

Table 2. Turbine Final Design Operating and Geometrical Conditions.

\begin{tabular}{|l|c|c|c|c|c|}
\hline & $\alpha_{1}$ & $\alpha_{2}$ & $\alpha_{3}$ & $\beta_{1}$ & $\beta_{2}$ \\
\hline Root & $0^{\circ}$ & $62.15^{\circ}$ & $12.12^{\circ}$ & $39.32^{\circ}$ & $51.13^{\circ}$ \\
\hline Mean & $0^{\circ}$ & $58.38^{\circ}$ & $10^{\circ}$ & $20.49^{\circ}$ & $54.96^{\circ}$ \\
\hline Tip & $0^{\circ}$ & $54.93^{\circ}$ & $8.52^{\circ}$ & $0^{\circ}$ & $58.33^{\circ}$ \\
\hline & & $\mathbf{1}$ & $\mathbf{2}$ & $\mathbf{3}$ & Unit \\
\hline $\mathrm{P}$ & & 3.54 & 2.49 & 1.856 & $\mathrm{bar}$ \\
\hline $\mathrm{T}_{0}$ & 1067 & 982.7 & 922 & $\mathrm{k}$ \\
\hline$\rho$ & & 1.155 & 0.883 & 0.702 & $\mathrm{~kg} / \mathrm{m}^{3}$ \\
\hline $\mathrm{A}$ & 0.0626 & 0.0833 & 0.1047 & $\mathrm{~m}$ \\
\hline $\mathrm{r}_{\mathrm{m}}$ & & 0.216 & 0.216 & 0.216 & $\mathrm{~m}$ \\
\hline $\mathrm{r}_{\mathrm{t}} / \mathrm{r}_{\mathrm{r}}$ & 1.24 & 1.33 & 1.43 & --- \\
\hline
\end{tabular}




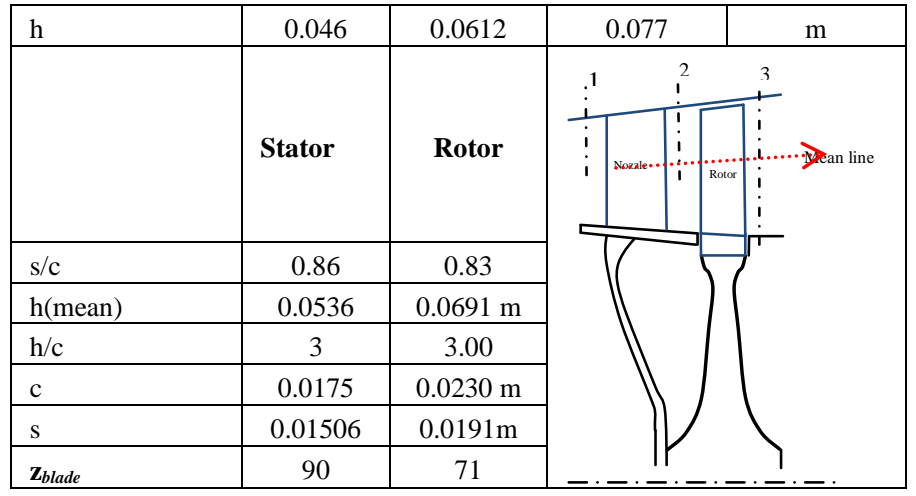

\subsection{Linear Cascade Design}

Based on the defined geometry for the rotor, it is possible to generate a linear cascade which represents the axial rotor, considering a line on the average height of the blade, the relative velocity field on the cascade and the associated boundary conditions. Thus, the angles of incidence, stagger angle and pitch cascade are defined in the average height of the blade. Figure 3 illustrates the basic gas turbine cascade configuration.

For the turbine cascade blade design, the camber line was estimated using the directions of relative velocities in the inlet and exit, obtained from the preliminary turbine design. This was done graphically by script written in Tcl/Tk language for interpreting by the software ICEM-CFD®. Given the chord length (c) and angles relative $\left(\beta_{1}\right)$ and $\left(\beta_{2}\right)$.

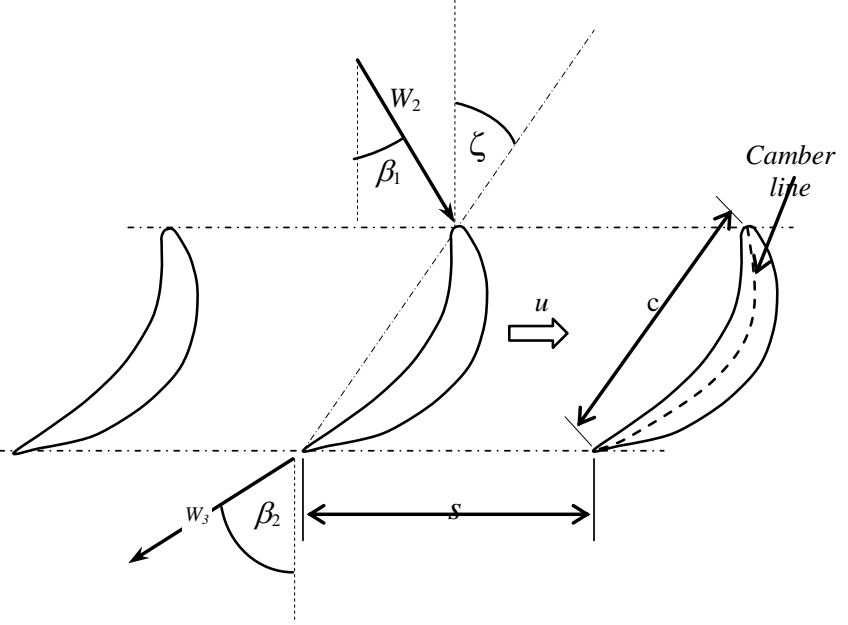

Figure 3. Cascade turbine configuration.

The tangents were brought to an intersection with each other and subdivided into equal distances. The envelope to the inner region of the connecting lines is the camber line. Once the camber line was constructed, a NACA 6519 profile was superimposed and the new profile was generated. The camber line was constructed, a NACA 6519 profile was superimposed and the new profile was generated.

\section{Integration Process CFD And Optimization}

CFD techniques have been developed over the past decades as a powerful analysis tool for quantification of flow fields in complex geometries, especially those found in Turbomachinery design. Such techniques have been used by the aeronautics industry since the 60ths, begging with the classical panel method with boundary layer interaction to account viscous effects. Nowadays, the use of computational fluid dynamics (CFD) for solving the full Navier-Stokes equations have become a common issue in several industrial design activities. Nevertheless, such computations may represent a bottleneck when a greater number of concurrent geometrical and flow parameters must be analyzed during the searching of good solutions for satisfying certain design objectives. Normally, such task is best accomplished by means of a suitable optimization algorithm (OA). But taking into account real life constraints - the available computational environment and budget - the number of comparative evaluations required by an OA may become prohibitive in a specific design situation (Praveen and Duvigneau, 2007).

To overcome this drawback, several strategies have been conceived for accelerating the optimization task, such as: (i) use of multiprocessing; (ii) use of better optimization algorithms; (iii) use of metamodels (surrogate models) for reducing the number of calls to the true solver model. From a strict engineering point of view, the 3rd strategy seems to be more inexpensive and universal, since it does not rely on costly hardware improvements neither on technical advances in optimization algorithms (da Silva et al, 2012).

\subsection{Optimization Process}

This work was used as algorithm the optimization stochastic, population-set based algorithm, capable of performing global optimization tasks efficiently, the CRSA, it was first proposed by (Price, 1977) and later improved by (Ali et al., 1997). Further improvements were introduced by (Manzanares et al., 2005).

The CRSA from an initial population of individuals over a consistent region of the problem promotes iterative substitutions of the worst individuals by the best, willing that the population shrink up around the global optimum. The points randomly generated in the space explored, following an iteration process converges to a global minimum by procedures purely heuristic (Ali et al., 1997; Ali and Törn, 2004). 


\subsection{Flow Calculation in CFD}

The blade cascade analysis still represents a fundamental tool in Turbomachinery design context. Relying on 2-D flow models, cascade flow computations are much faster than 3-D models of similar physical complexity. For testing purposes, the CRSA methodology is applied now to a simple case of blade cascade design.

Relevant resulting quantities include the pressure distribution on the blade surface, the flow deflection angle, energy losses, contours of number Mach, lift and drag blade forces.

The flow computations were made using the CFD software FLUENT®. The required meshes were generated by the software ICEM-CFD, through the editing commands in Tcl/Tk.

Prior to optimization process certain steps should be prepared, for example, the definition of a computational domain and mesh generation. The 2-D meshes are generated by a script written in Tcl/Tk language that can be modified by the optimizer and interpreted by the software ICEM$\mathrm{CFD}{ }^{\circledR}$. Care is taken in the refinement of the mesh near the wall in order to properly quantify the friction stresses. Figure 4 shows the computational periodic zone of linear cascade.

The organic fluid type is defined based on the thermodynamic properties, density and dynamic viscosity. The initial hypotheses, the discretized forms of transport equations are solved iteratively, and the solution must converge.

Real gases, as opposed to a perfect or ideal gas, exhibit properties that cannot be explained entirely using the ideal gas law. The NIST (National Institute of Standards and Technology) real gas model that use the Thermodynamic and Transport Properties of Refrigerants and Refrigerant Mixtures (Lemmon et al., 2006) as an ANSYS FLUENT® shared library (REFPROP v7.0) was used to evaluate the thermodynamic and transport properties of the working fluids.

The REFPROP v7.0 database employs accurate purefluid equations of state that are available from NIST. These equations are based on the following three models: Modified Benedict-Webb-Rubin (MBWR) equation of state, Helmholtz-energy equation of state and extended corresponding states (ECS).

In this study will be used to model real gas proposed by Benedict - Rubin. Recently, (Colonna et al., 2006), was analyzed using CDF code, a cascade of a stator of a radial turbine with three different fluid models; the simple polytrophic ideal gas law, the Peng-Robinson-Stryjek Vera cubic EoS and the state-of-the-art Span-Wagner EoS. According (Colonna et al., 2006) the fluid dynamic results are very similar for the computations employing the Span-
Wagner and Peng - Robinson Stryjek-Vera EoS. The proposed model MBWR, is very similar to the last.
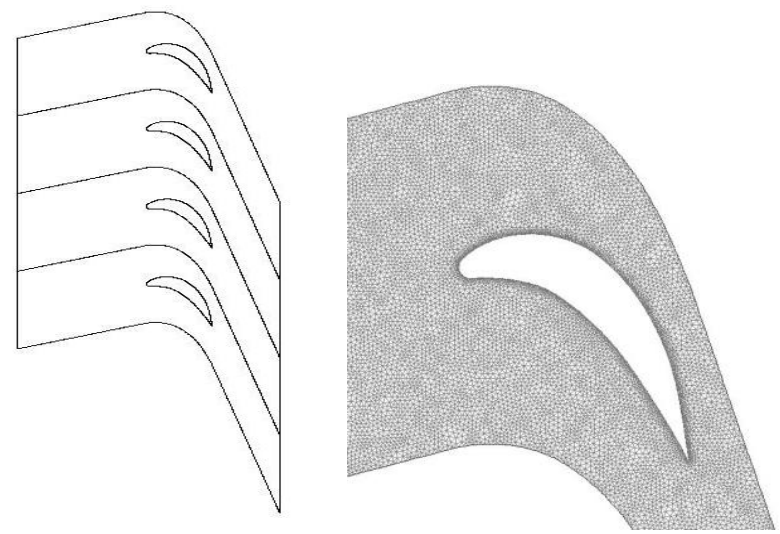

Figure 4. Periodic Channel and Unstructured mesh (40000 cell)

The mass flow or velocity is set at the cascade inlet and the pressure at the cascade outlet. Periodic boundary conditions are considered for reducing the computational domain to a unique periodic region around an airfoil. The turbulence model Spalart-Allmaras (SA) with wall functions is chosen since these enable realistic responses to aerodynamics problems (Azevedo et al., 2003; Spalart and Allmaras, 1992).

The drag and lift coefficients are calculated with basis on the magnitude of the mean velocity vector. The drag coefficient is computed: first, the difference of total pressure between cascade inlet and outlet is evaluated and the following loss coefficient $\zeta \mathrm{r}$ is computed (Vavra, 1974).

$$
\zeta_{r}=\frac{P_{1}-P_{2}}{(\rho / 2) W_{2}^{2}}
$$

The outlet mass average quantities are evaluated by control line (line/rake) located at a distance of a chord length from the trailing edge.

Hence, the drag coefficient is computed by the following relationship:

$$
C_{d}=\frac{\zeta_{r} \cos ^{3} \beta_{\infty}}{(s / c) \cos ^{2} \beta_{2}}
$$

This methodology for calculation the drag coefficient avoids numerical errors associated with the integration of the blade surface forces.

The lift coefficient is then computed:

$$
C_{l}=2(s / c)\left[\tan \beta_{1}+\tan \beta_{2}\right] \cos \beta_{\infty}-C_{d} \tan \beta_{\infty}
$$

Several efficiencies are used to compare the performance of the turbine stage; the most common definition is the adiabatic efficiency. However, in cases involving cascade can be used as criteria's of efficiency as total pressure loss 
coefficient and diffusion factor. On the other hand, the lift and drag ratio maximum $\left(C_{l} / C_{d}\right)$, can be used as way evaluating the loading aerodynamic in the cascade.

\subsection{Process Integration Methodology}

According to (Quoilin and Lemort, 2014), to optimize complex systems, it is necessary to use methods of process integration, this is, CFD flow calculation and optimization algorithms. These methodologies contribute significantly to the development of engineering optimal designs.

The CRSA was adopted as a direct optimizer, an initial population of $10(n+1)$ individuals were adopted, where $n$ is the number of design variables (Stagger angle $\zeta$ and pitch $\mathrm{s}$ ). The convergence criterion was 1\% (absolute difference between the function values in the worst and best parts of the population or a maximum number of evaluations equal to 500$)$.

The optimization process was obtained by integrating the CRSA with the CFD-Fluent ${ }^{\circledR}$ (CRSA $\rightarrow$ script.dat $\rightarrow$ ICEM-CFD ${ }^{\circledR} \rightarrow$ Journal.file $\rightarrow$ Fluent ${ }^{\circledR}$ ). Used, commands in DOS, for running in FORTRAN through the CRSA, a "script" of commands in $\mathrm{Tcl} / \mathrm{tk}{ }^{\circledR}$ is written to interpretation in ICEM-CFD, one computational mesh is generated with variations of stagger angle and pitch for a profile known. Through the script, also provides information about the parameters mesh in regions close to the wall, then a file "journal.jou", is edited with information for program execution Fluent: number iteration, criteria convergence, turbulence model, boundary conditions and the formulations for drag and lift coefficients (2) and (3).

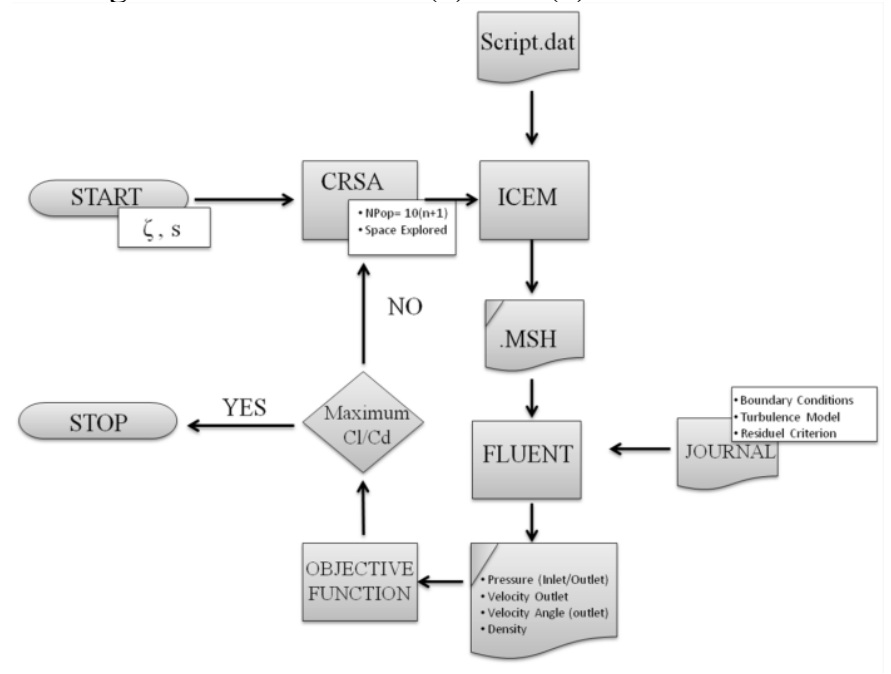

Figure 5. Process Integration Structure.

Have been considered critical temperatures of organic fluids in the boundary conditions at the input as: R245fa $\left(154^{\circ} \mathrm{C}\right)$ and Toluene $\left(318.64^{\circ} \mathrm{C}\right)$.

\subsection{Optimization Process Results}

Table 3 presents the ranges for the generation of the plan of experiments considering the variables of the design: stagger angle and pitch cascade to two organic fluids: R245fa, Toluene.

The optimization process was initiated with a population of $30, \mathrm{NPOP}=10(\mathrm{n}+1), \mathrm{n}=2$ (stagger angle and pitch cascade) as criteria convergence was used the residual of $\varepsilon=$ 0.0001 , value between the two best values found of $C_{l} / C_{d}$ in the optimization process. One first analyzes was defined the intervals for stagger angle and pitch cascade.

Table 3. Intervals to the Population Generation

\begin{tabular}{|c|c|c|}
\hline Fluids organic & $\zeta$ Stagger angle & s (m) pitch cascade \\
\hline R245fa and Toluene & $41.00-44.66$ & $0.0081-0.015$ \\
\hline
\end{tabular}

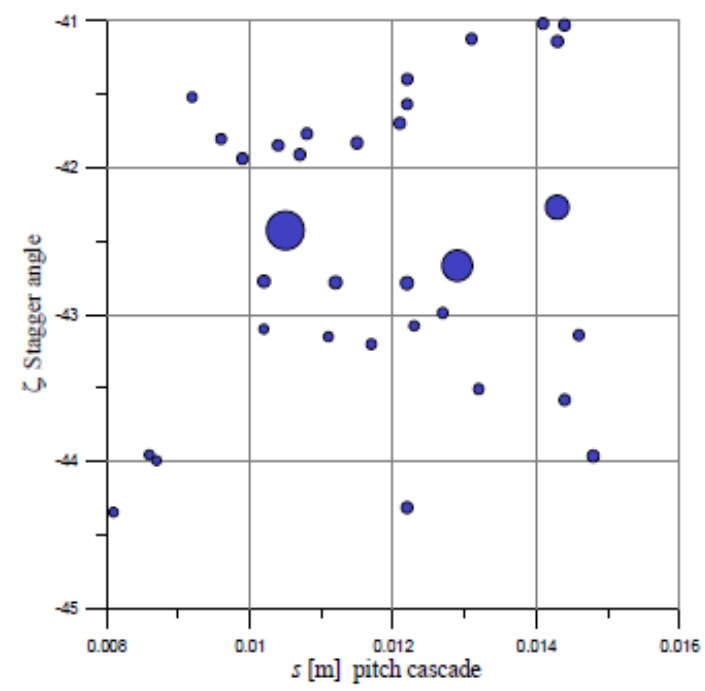

Figure 6. Bubbles plot of $C_{l} / C_{d}$ to R245fa.

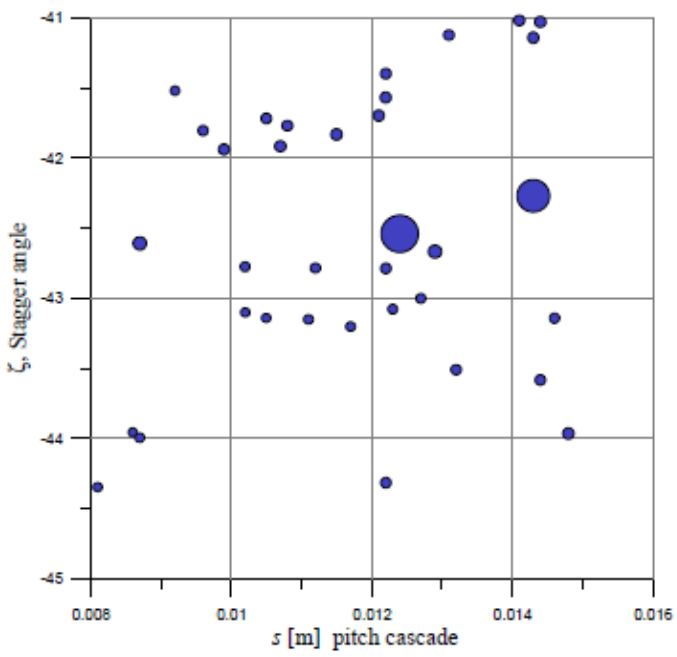

Figure 7. Bubbles plot of $C_{l} / C_{d}$ to Toluene. 
After the optimization process using the CRSA (Controlled Random Search Algorithm), and considering an initial population of 30 randomly design variable, with the aim of maximizing the relation $C_{l} / C_{d}$, is presented in Figures 6 and 7 in the bubble plot, values $C_{/} / C_{d}$ inside the range of variation of stagger angle and pitch cascade for the R245fa and Toluene.

Based on the maximum values of $C_{l} / C_{d}$ presented in Figures. 6 and 7, was reduced search interval and also generated a new population with 30 design variables. Table 4 shows the new ranges for the two organic fluids.

Table 4. Intervals for the two Organic Fluids.

\begin{tabular}{|c|c|c|}
\hline & $\zeta$ Stagger angle & s (m) pitch cascade \\
\hline R245fa & $42.40-42.50$ & $0.0081-0.015$ \\
\hline Toluene & $42.00-42.60$ & $0.0081-0.015$ \\
\hline
\end{tabular}

Table 5 present optimum values of the coefficients of drag and lift, quantified by the aerodynamic load, $C_{/} / C_{d}$. Optimization processes are initialized based on the profile NACA 6519, gas turbine cascade.

The results of aerodynamic coefficients are calculated using (2) and (3), where the values of the deflection angles of the flow cascade, and variations in total pressure has been calculated in the inlet and outlet regions of the cascade. Results obtained from the optimization process with CRSA.

Table 5. Results of Optimization Process From CRSA.

\begin{tabular}{|c|c|c|c|c|c|c|}
\hline $\begin{array}{c}\text { Fluid } \\
\text { organic }\end{array}$ & $\begin{array}{c}\boldsymbol{\zeta} \\
\begin{array}{c}\boldsymbol{\zeta} \\
\text { Stagger } \\
\text { angle }\end{array}\end{array}$ & $\begin{array}{c}\mathbf{s}(\mathbf{m}) \\
\text { pitch } \\
\text { cascade }\end{array}$ & $\boldsymbol{C}_{\boldsymbol{l}}$ & $\boldsymbol{C}_{\boldsymbol{d}}$ & $\boldsymbol{C}_{\boldsymbol{l}} / \boldsymbol{C}_{\boldsymbol{d}^{*}}$ & $\begin{array}{c}\boldsymbol{C}_{\boldsymbol{l}} / \boldsymbol{C}_{\boldsymbol{d}} \\
\text { optimum }\end{array}$ \\
\hline \multirow{2}{*}{$\mathrm{R} 245 \mathrm{fa}$} & 43.2630 & 0.01025 & 1.0128 & 0.0353 & 28.6931 & \\
\cline { 2 - 7 } & 42.4710 & 0.01440 & 0.7003 & 0.0027 & & 262.0300 \\
\hline \multirow{2}{*}{ Toluene } & 43.2630 & 0.01025 & 1.4020 & 0.0667 & 21.0283 & \\
\cline { 2 - 7 } & 42.4849 & 0.00860 & 0.3181 & 0.0016 & & 198.5575 \\
\hline
\end{tabular}

*Base cascade: NACA 6519 ; Stagger angle $\zeta=43.2630^{\circ}$ and pitch, $\mathrm{s}=0.01025[\mathrm{~m}]$

In the results presented in Table 5, it is possible to observe that the pitch of the R245fa cascade has greater influence on the increase in the aerodynamic performance. However, the stagger angle, in both fluids, had little influence on the cascade efficiency.

It should be noted also, that the cascade initial design, is based on the cascade calculation of a gas turbine flow (Price, 1977), therefore, a consequence of the values of $C_{/} / C_{d}$ ratio has improved considerably from the initial design to the optimized for ORC.

This analyze can be applied to axial rotor, if we consider the medium diameter $D_{m}=0.432 \mathrm{~m}$. then $(\mathrm{Z}=\pi \mathrm{D} / \mathrm{s})$, the rotor using R245fa it would have near 94 blades and for Toluene 157 blades. Remember the design the gas turbine was the 71 blades, considering the same relation s/c. This criterion to optimize the load aerodynamic using the $C_{l} / C_{d}$ relation is used in cascade plane, but performance in rotor of turbine axial should be applied the isentropic efficiencies in the rotor.

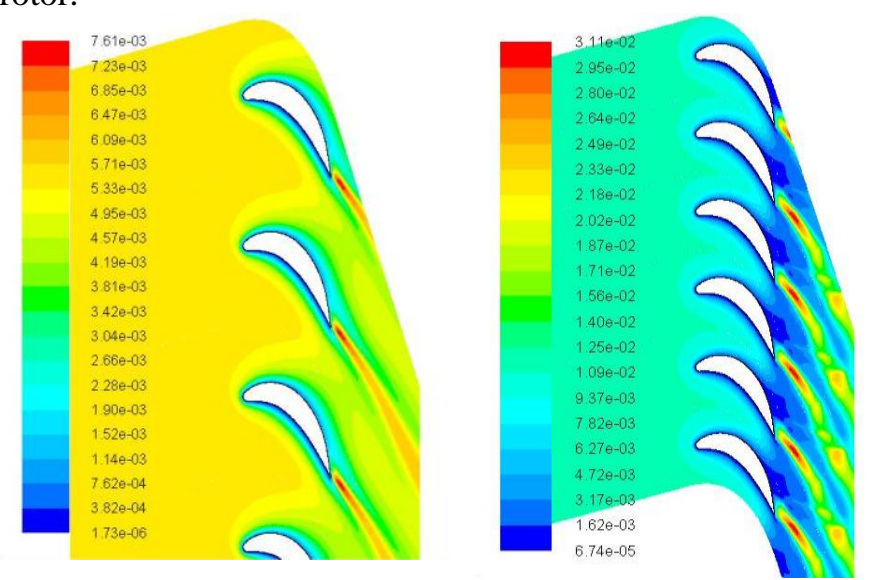

Figure 8. Contours of Viscosity Turbulent, R243fa (a); Contours of Viscosity Turbulent, Toluene(b).
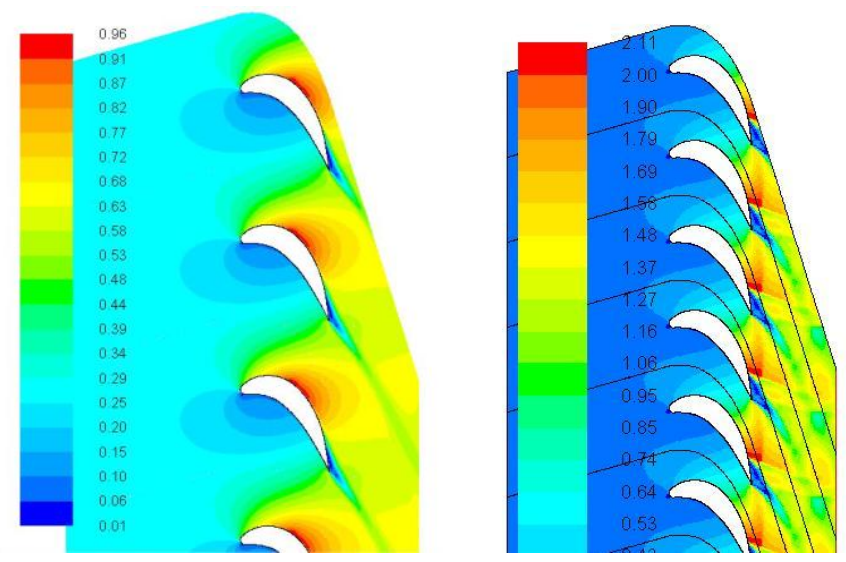

Figure 9. Contours of Mach number, R243fa (a); Contours of Mach number, Toluene (b).

Figures 9a and 9b, shows the contours of viscosity turbulent, where the maximum values are concentrated in the trailing edge region, the toluene cascade present major intensity of vortices. In the Figures 10a and 10b, show the differences in the Mach number, the Toluene cascade can operate with Mach larger than one, frequently this machine operates with high number mach.

\section{Conclusions}

Based on the design methodology of a gas turbine cascade, it is possible, through optimization techniques and CFD flow calculations, to find an optimum cascade to work with different organic fluids. As a first approach, we analyzed two fluids, with two design variables (pitch and stagger angle). For the optimization process, we used a heuristic algorithm CRSA (Controlled Random Search Algorithm), being effective in finding the optimal solution. Results of a $C_{l} / C_{d}$ ratio showing the effects of the design variables (pitch and stagger angle) for two organic fluids were reported. As 
can be seen, is necessary optimize the aerodynamic profile changes the configuration of NACA 6519, and introduce the function of camber to correct the separation of the boundary layer in the trailing edge.

Future work will be carried out in order to introduce the tri- dimensional effects on the ORC turbine stator - rotor, aiming to optimize the isentropic efficiencies of this kind of machines. The optimization methodology allows to adapt the preliminary design of gas turbine for the design of cascades with different organic fluids, for analyzing the behavior of the aerodynamic forces and geometric variations in the cascade.

\section{Acknowledgements}

This work was carried out with the support of CNPQ/SAAB/CISB and MDH University.

\section{References}

M. Ali, A. Törn, and S. Viitanem. A Numerical Comparison of Some Modified Controlled Random Search Algorithm. Journal of Global Optimization, 11(4):377-385, 1997. doi:10.1023/A:1008236920512.

M. Ali and A. Törn. Population Set-Based Optimization Algorithms: Some Modifications and Numerical Studies. Computer and Operations Research, 31(10):1703-1725, 2004. doi: 10.1016/S0305-0548(03)00116-3.

J. L. F. Azevedo, E. D. V. Bigarella, F. C. Moreira, and E. Basso. Implementação e Teste de Modelos de Turbulência para Aplicações Aeroespaciais em Malhas Não Estruturadas. In CIBEM 6 - VI Congresso Ibero-Americano de Engenharia Mecânica, 2003, Coimbra, 1:705-710, 2003.

R. Crowe. Capturing waste heat with rankine cycle systems. Renewable Energy World.com, 2011.

P. Colonna, S. Rebay, J. Harinck, and A. Guardone. Real-Gas Effects in ORC Turbine Flow Simulations: Influence of Thermodynamic Models on Flow Fields and Performance Parameters. In Proceedings of the European Conference on Computational Fluid Dynamics 2006, Egmond aan Zee, The Netherlands, September, 2006.

E. Lemmon, M. Huber, and M. McLinden. NIST Standard Reference Database 23: Reference Fluid Thermodynamic and Transport Properties-REFPROP, Version 9.0, National Institute of Standards and Technology, Standard Reference Data Program, Gaithersburg, 2010.

V. Lemort, S. Quoilin, and C. Pire. Experimental investigation on a hermetic scroll expander. In Proceedings of the 7th International IIR Conference on Compressors. 2009.

N. Manzanares-Filho, C. A. A. Moino, and A. B. Jorge. An Improved Controlled Random Search Algorithm for Inverse Airfoil Cascade Design. In Proceedings of the 6th World Congress of Structural and Multidisciplinary Optimization, Paper No 4451, Rio de Janeiro, Brazil, 2005.

C. Praveen and R. Duvigneau. Radial Basis Functions and Kriging Metamodels for Aerodynamic Optimization. INRIA; 40 pages. RR-6151; France, 2007.
W. L. Price. A controlled random search procedure for global optimisation, Computer Journal 20(4):367-370,1977.

X. Qin, L. Chen, F. Sun, and C. Wu. Optimization for a steam turbine stage efficiency using a genetic algorithm. Applied Thermal Engineering, 23(18):2307-2316, 2003. doi: 10.1016/S1359-4311(03)00213-8.

S. Quoilin, S. Declaye, and V. Lemort. Expansion Machine and fluid selection for the Organic Rankine Cycle. In Proceedings 7th International Conference on Heat Transfer, Fluid Mechanics and Thermodynamics, Antalya, Turkey, 2010.

S. Quoilin and V. Lemort. Technological and Economical Survey of Organic Rankine Cycle Systems. In Proceedings $5^{\text {th }}$ European Conference Economics and Management of Energy in Industry, 2014.

H. Saravanamuttoo, G. Rogers, and H. Cohen. Gas Turbine Theory, 5th ed. Harlow: Prentice-Hall, 2001.

E. R. da Silva, N. Manzanares-Filho, and R. G. Ramirez Camacho. Metamodelling approach using radial basis functions, stochastic search algorithm and CFD - application to blade cascade design. International Journal of Mathematical Modelling and Numerical Optimisation, 3(1/2):87-92, 2012. https://doi.org/10.1504/IJMMNO.2012.044715.

P. Spalart and S. Allmaras. A One-equation Turbulence Model for Aerodynamics Flows. AIAA Aerospace Sciences Meeting \& Exhibit, 30., Reno. In Proceedings Washington, DC: AIAA, 1992.

M. Vavra. Aero-Thermodynamics and Flow in Turbomachines, Reprint of the ed. Published by Wiley, New York, ISBN 088275-189-1. 